\title{
ÍNDICE DE MATERIAS
}

P R E F A C I O XV

I N T R O D U C C I Ó N I

C O N Q U I T A Y C O L O I Z A C I Ó N D E L

N U E V O M U N D O I 5

O R G A N I Z A C I Ó N C O L O N I A L 2 I

ACOSTA, EL PADRE J OSÉ DE ( I $540-$ I 600$) 25$

Historia natural y moral de las Indias [I 589] (I 590) 25

Que se halla en los antiguos alguna noticia de este

Nuevo Mundo 26

Lo que sintió Platón de esta India Occidental 28

Vinieron por tierra los primeros pobladores de Indias 28

Tres géneros de gobierno y vida en los indios 30

A L VA IXTLILXÓCHITL, FERNANDO DE

( ¿ I 578 ? - I 648 ) 32

Historia de la nación chichimeca [1616?] 32

El amor criminal de un rey 32

La reina adúltera 35

GARCILASO D E LA VEGA, E L I C A

( I $539-$ I 6 I 6 ) 38

Comentarios reales de los Incas, Primera Parte (I609) 38

Criaban los hijos sin regalo ninguno 39 
Huayna Cápac hace rey de Quito a su hijo Atahualpa 40 Testamento y muerte de Huayna Cápac y el pronóstico de la ida de los españoles 42

Comentarios reales de los Incas, Segunda Parte: Historia general del Perú (I6I7) 44

La venganza que Aguirre hizo de su afrenta 44

LAS CASAS, BARTOLOMÉ De ( ¿̇ 474 ? - I 566 )

Historia de las Indias [I 527-?] ( I 876) 49

Que trata de la población de Cuba $5 \mathrm{I}$

Que trata de la pasada de los españoles a la isla de Cuba

D ÍAZ DEL CASTILLO, BERNAL（I $492-\dot{\text { I }} 583$ ? ) 56

Historia verdadera de la conquista de la Nueva España

[I 568] (I632) 56

Jerónimo Aguilar y Gonzalo Guerrero 56

Doña Marina 60

Las cercanías de México [Tenochtitlán] 62

México, la plaza de Tlatelolco 62

C O RTÉS， HERNÁN（I 485 - I 547 ) 64

Cartas de relación sobre el descubrimiento y conquista de la Nueva España [I 519-I 526] (I 852) 64

Preparaciones para marchar hacia el interior del país 65

Los tlaxcaltecas se convierten en aliados 66

Moctezuma, prisionero de Cortés, y de la profecía de Quetzalcóatl 67

FERNÁNDEZ DE OVIEDO, GONZALO

$$
\text { ( I 479-I 557) } 69
$$

Historia general y natural de las Indias (vol. I, I 535;

vol. 2, I 537) 69

La rebelión del cacique Enrique [Enriquillo] 69

Beçerrillo y Leonçico 74

GARCI LAS O D E L A VEGA, E L I NCA

$$
\text { ( I } 539 \text { - I } 6 \text { I } 6 \text { ) } 78
$$

Comentarios reales de los incas, Primera Parte (I609) 79

El naufragio de Pedro Serrano 79 
B ENAVENTE, FRAY TORIBIO DE (M OTOLINÍA)

$$
\text { ( ¿ I } 490 \text { ? - I } 569 \text { ) } 84
$$

Historia de los indios de la Nueva España [I 54I] (I 859) 84

De los diversos pareceres que hubo sobre administrar el sacramento del bautismo, y de la manera que se hizo los primeros años 84

De cómo los indios se confiesan por figuras y caracteres 87

De dónde comenzó en la Nueva España el sacramento del matrimonio, y de la gran dificultad que hubo en que los indios dejasen las muchas mujeres que tenían 87

De la humildad que los frailes de San Francisco tuvieron en convertir a los indios y de la paciencia que tuvieron en las adversidades 89

N Ú Ñ Z C A B EZ A D E VACA, A L VAR

$$
\text { ( ¿ I } 490-\text { I } 559 \text { ?) } 90
$$

Naufragios [entre I 537 y I 540] (I 542) 90

Cuando partió la armada 9I

De lo que nos acaeció en la isla de Malhado 92

De cómo nos apartaron los indios 93

Cómo otro día nos trajeron otros enfermos 94

De otra nueva costumbre 95

De cómo se mudó la costumbre de recibirnos 96

De lo que sucedió a los demás que entraron en las Indias 96

A GUADO, FRAY PEDRO DE ( ¿ I 538 ? - I $585+$ ) 99

Recopilación historial [I575 y I58I] (I906 y I9I3-I9I5) 99

El notable hecho de una mujer española 99

S C H M I DEL, ULR I C O ( ¿ I 5 I O - I 579 ? ) IO2

Historia y descubrimiento de el Río de la Plata y Paraguay

$$
\text { [I 534-I 5 54] (I706) IO2 }
$$

De España a las Canarias $\mathrm{IO} 3$

De la población de Buenos Aires IO4

Del sitio, toma y quema de la ciudad de Buenos Aires 104

Prosiguen la navegación al río Paraná Io4

Llegan a los scherves I05

En busca de las amazonas 106

El retorno 107 
F U ENTES Y G U Z MÁN, FRANCISCO ANTONIO DE

$$
\text { ( ¿ I } 642 \text { - I } 699 \text { ?) IO8 }
$$

Historia de Guatemala; o Recordación florida [siglo XVII]

$$
\text { ( } 1882 \text { - } 883 \text { y I932) ro8 }
$$

De la temerosa y grave inundación que sobrevino a la ciudad de

Guatemala Io9

CARVAJAL, FRAY GASPAR DE ( ¿ I 504 ? - I 584$)$ II 5

Descubrimiento del Río de las Amazonas

$$
\text { [I 54 I-I 542] (I 894) I I } 5
$$

La navegación por el Amazonas y sus peligros $\quad$ II 7

Noticias del indio sobre las amazonas II9

C IEZ A D E LEÓN, PEDRO

$$
\text { ( I } 520 \text { Ó I } 522-\text { I } 554 \text { ) I2I }
$$

La Crónica del Perv [I 550] (I 554) I 2 I

La ciudad del Cuzco I 2 I

Un cacique en lucha con los demonios I 24

R O D R ÍG UEZ FREYLE, J U A N ( I 566-¿ I 640 ? ) I 28

Conquista y descubrimiento del Nuevo Reino de Granada

$$
\text { [I636] (I859) I } 28
$$

El vestido de la manga de grana $\quad$ 2 8

S I M Ó N, F R A Y P E D R O ( ¿ N . I 574 ?) I33

Noticias historiales de las conquistas de Tierra Firme en las Indias Occidentales (1627) 133

Seres extraños 134

Historia de amor $\quad \mathbf{3} 5$

El Dorado I36

S UÁREZ DE PERALTA, J U AN ( ¿ I 537 ? - I 590 ) I38

Tratado del descubrimiento de las Indias y su conquista [I 589 ] ( 1878 ) I38

Agravio que hizo Gil González a su hermano I 39

OVIED O Y B A Ñ O S, J O SÉ DE ( I 67 I-I 738 ) I4 I

Historia de la conquista y población de la provincia de Venezuela ( I723) I4 I

La rebelión del negro Miguel I4I 
Saquean los corsarios la ciudad de Santiago de León [Caracas] I44

G L O S A R I O I49

EDICIONES EMPLEADAS EN

LAS SELECCIONES I 53

B I B L I O G R A F Í A I 55

ÍNDICE ANALÍTICO I59 
THIS PAGE INTENTIONALLY LEFT BLANK 